ISSN 1991- 8690

website : http:// jsci.utq.edu.iq

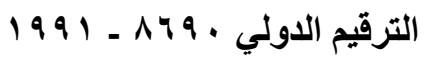

Email: utjsci@utq.edu.iq

\title{
Structural and Electronic Properties of Donor-Acceptor Molecular System: B3LYP/ DFT Calculations
}

\author{
Basim Abdullattif Ghalib \\ Afrah Abdulameer Mohammed
}

\author{
Falah Hassan Hanon \\ Hamid Ibrahim Abbood
}

\begin{abstract}
$\underline{\text { Abstract }}$
Present work deals with the structural and electronic properties of trifluorocarbon-nitro CF3-NO as a donoracceptor molecular system. Density functional theory at the three parameters B3LYP level of theory was employed with various basis sets to determine and calculate some structural and electronic properties for this molecular system. The calculations include the geometrical parameters of the studied structures. And some electronic properties of these were investigated include the total energy, electronic states, ionization potential, electron affinity, electro chemical hardness, softness and electrophilic index. The results showed that 6-31G $(\mathrm{d}, \mathrm{p})$ level of theory gave good agreement values of geometrical parameters with experimental data in compared with other levels.
\end{abstract}

Key words: DFT, energy gap, ionization potential, hardness and IR-spectrum.

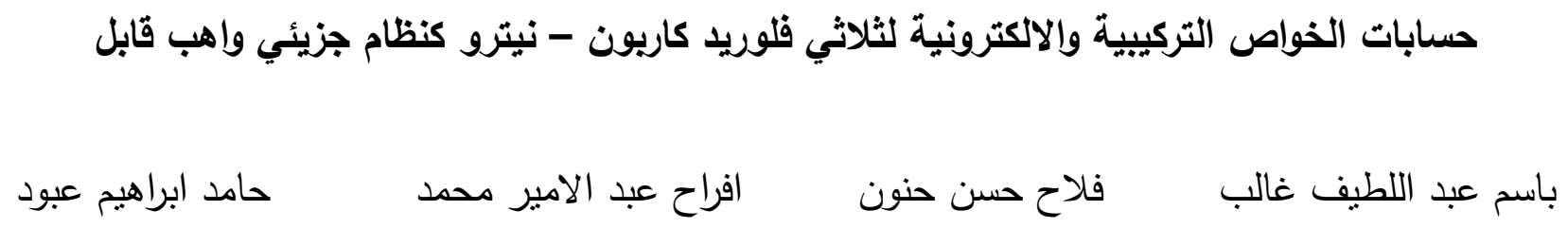

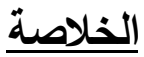

البحث الحالي يهدف الى معالجة الخواص التركيبية والاكترونبة لثلاثي فلوروكاربون-نيترو كنظام جزيئي واهب-قابل. تم تطبيق نظرية دالة الكثافة عند

مستوي المعاملات الثنلاث B3LYP وبدوال اساس مختلفة لتحديد وحساب بعض الخواص التركيبية و الاكترونية للنظام الجزيئي الدذكور . تضمنت الحسابات المعاملات الهندية للتراكيب قيد الدراسة. الخواص الالكترونية المحسوبة في هذا البحث تضدنت الطاقة ألكلية الحالات الالكترونية، جهد التأين، الالفة

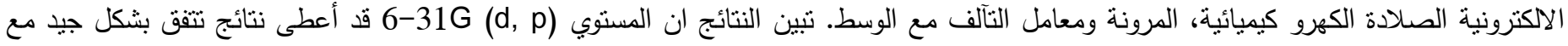

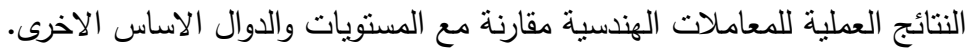

\section{Introduction}

The researches based on the charge transfer has long been recognized as the key process in many fields of chemistry(1), physics(2-4), and biology (5-7) monographs(8-10). This work stands on the design of donor-acceptor and then can in future contact the donor and acceptor by a either $\pi$ or $\sigma$ bridges to determine the quantity of charge transfer. A convenient model system often used to probe the mechanism of charge transfer in molecular objects with nanoscale dimensions comprises a donor (D) and an acceptor (A) of electrons or holes connected by molecular bridge (B) (11- 14). The number and variety of such donor-bridge acceptor (DB-A) systems have grown explosively in recent years (15-17). Molecular bridges linking between an electron donor and an electron acceptor are known to control charge transport in molecular systems. Extensive studies emphasized the role of different factors controlling the charge transport mechanism of donorbridge- acceptor systems including inter-site electronic coupling, electronic energies and electronic - nuclear coupling. Present work focuses on calculating the structural and electronic properties of $\mathrm{CF}_{3}-\mathrm{NO}$ as a 
donor-acceptor system and compute the amount of charge transport as a measure the maximum electronic charge that saturates the system, it is a measure of the electronic transfer that a system may accept.

\section{Computational Details}

Density functional theory has been used in this work to calculate the electronic properties of the studied molecules at (B3LYP) functional with various basis sets. The geometry optimization, energies and IRspectrum have been done using Gaussian 09 program (18).

For a normalized wave function $\Psi$, the particle density is given by $\rho(r)$

$\rho(r)=\sum_{i}^{n i}\left[\Psi_{i}(r)\right]^{2}$

Where ni is the number of electrons in orbital (i), and the summation is over the occupied molecular orbital's .The kinetic energy of the system is (20):

$T[\rho]=T_{s}[\rho]+J[\rho]+V_{e n}[\rho]+E_{X c}[\rho]$

Where $T_{s}[\rho], I[\rho], V_{e n}[\rho]$ and $E_{X C}[\rho]$ are the kinetic energy of non interacting electron system, classical coulomb energy, and exchange-correlation energy, respectively, can be written as:

$E_{X C}[\rho]=\int(\rho) E_{X C}[\rho] d r$

$T_{s}[\rho]=-\frac{1}{2} \sum_{i}\left\langle\emptyset_{i}\left\|\nabla^{2}\right\| \emptyset_{i}\right\rangle$

$J\left[\rho_{0}\right]=\frac{1}{2} \iint \frac{\rho_{0}\left(r_{1}\right) \rho_{0}\left(r_{2}\right)}{\| r_{1}-r_{2} \mid} d r_{1} d r_{2}$

$V_{e n}\left[\rho_{0}\right]=\frac{1}{2} \iint \frac{\rho_{0}\left(r_{1}\right) \rho_{0}\left(r_{2}\right)}{\left|r_{1}-r_{2}\right|} d r_{1} d r_{2}+E_{X C}[\rho]$

According to B3LYP function, the exchange correlation energy $E_{X C}^{B 3 L Y P_{\text {is }}}$ given by $(21)$ :

$E_{x c}^{B 3 L Y B}=E_{x c}^{L D A}+a_{0}\left(E_{x}^{H F}-E_{x}^{L D A}\right)+a_{x}\left(E_{x}^{G G A}-E_{x}^{L D A}\right)+a_{c}\left(E_{c}^{G G A}-E_{c}^{L D A}\right)$

Where the three parameters: $\mathrm{a}_{0}=0.20, \mathrm{a}_{\mathrm{x}}=0.72$ and $\mathrm{a}_{\mathrm{c}}$ $=0.81$.

The ionization potential (IP) and the electron affinity (EA) of the molecule are calculated according to the following relations (Koopman's theorem ) (22):

$\mathrm{IP}=\mathrm{E}_{\mathrm{HOMO}}$

$\mathrm{EA}=\mathrm{E}_{\mathrm{LUMO}}$

Where $\mathrm{E}_{\mathrm{HOMO}}$ and $\mathrm{E}_{\mathrm{LUMO}}$ are the high occupied molecular orbital and lower unoccupied molecular orbital energies, respectively. The electronic chemical potential $(\chi)$, the chemical hardness $(\eta)$ and the softness (s) are given by (23):
$\chi=\frac{I P+E A}{I P^{2} E A}$
$\eta=\frac{\mathbb{1}^{2}}{2 \eta}$

And the electrophlicity index $(\omega)$ of the molecular is given by $(23,24)$ :

$\omega=\frac{\not^{2}}{2 \eta}$

\section{Results and Discussion}

In figure $1, \mathrm{CF}_{3}$ molecule is an acceptor and $\mathrm{NO}$ is a donor molecule, this choice is due to the electronic distribution of the two structures. The geometrical structure of $\mathrm{CF}_{3}-\mathrm{NO}$ as a acceptor-donor molecular system was optimized at B3LYP density functional theory. Table 1 represents the B3LYP/6-31G(d, p) calculations of total energy in (a. u), symmetry and total dipole moment in ( Debye) for donor, acceptor and donor-acceptor molecular systems. It is clear that from table 1, the total energy for each molecule depends on the number of atoms in the molecule, it is decreasing with the increase of atoms number that the molecule included. Table (1) shows also the symmetry of the studied structures, the trifluorocarbon molecule is a planar with inversion center and it has $\mathrm{D}_{3 \mathrm{~h}}$ symmetry (high symmetry), and this is the reason that this molecule has not dipole moment as seen in table 1, while the nitro monoxide molecule has infinity $\mathrm{C}_{\text {infv }}$ symmetry (low symmetry) and the donor-acceptor system has $\mathrm{C}_{1}$ symmetry with dipole moment equals to (0.1458 Debye). All donor, acceptor and acceptor-donor have not imaginary frequencies, this may refers to good geometrical optimization obtained from the best B3LYP with large 6-31G(d, p) level of theory.

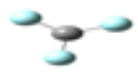

Acceptor

Donor

\section{Acceptor-Donor}

Figure (1): The optimized structure of acceptor-donor molecular system 
Table 1: Total energy, symmetry and total dipole moment for structures

\begin{tabular}{|c|c|c|c|}
\hline Species & $\begin{array}{c}\text { Total } \\
\text { Energy } \\
(\mathbf{a . u})\end{array}$ & Symmetry & $\begin{array}{c}\text { Total D. } \\
\text { M( Debye) }\end{array}$ \\
\hline $\mathrm{NO}(\mathrm{D})$ & -129.45296 & $\mathrm{C}_{\mathrm{infv}}$ & 0.5570 \\
\hline $\mathrm{CF}_{3}(\mathrm{~A})$ & -337.10016 & $\mathrm{D}_{3 \mathrm{~h}}$ & 0.0000 \\
\hline $\mathrm{CF}_{3}-\mathrm{NO}(\mathrm{A}-\mathrm{D})$ & -467.35868 & $\mathrm{C}_{1}$ & 0.1458 \\
\hline
\end{tabular}

The results of geometrical parameters included the bond length (in Angstrom) and bond angles in (degree) are declare in table 2. The computational levels of theory used in this work give good results of length linking between donor and acceptor, the bond $\mathrm{C}-\mathrm{N}$ obtained from $6-31 \mathrm{G}(\mathrm{d}, \mathrm{p})$ equals $\left(1.457 \mathrm{~A}^{0}\right)$ in a good agreement with experimental value $\left(1.452 \mathrm{~A}^{0}\right)$, F-C-F bond equals $120^{\circ}$ (15). Other levels of theory gave approximately values of these parameters nearly to experimental results.

Table 2: Geometrical parameters for donor-acceptor system

\begin{tabular}{|l|l|l|l|l|l|l|l|l|l|}
\hline Species & Bond & ST0-3G & $3-21 G$ & $4-21 G$ & $6-31 G$ & $6-31 G(d)$ & $\begin{array}{c}6-31 G \\
(d, p)\end{array}$ & $6-311 G$ & $\begin{array}{l}\text { Exp } \\
(15)\end{array}$ \\
\hline N0 & N-0 & 1.242 & 1.229 & 1.228 & 1.229 & 1.215 & 1.226 & 1.222 & 1.225 \\
\hline $\mathrm{CF}_{3}$ & C-F & 1.365 & 1.355 & 1.368 & 1.382 & 1.379 & 1.370 & 1.380 & 1.370 \\
\cline { 2 - 10 } & F-C-F & 119.99 & 120.0 & 119.99 & 120.0 & 120.0 & 120.0 & 119.99 & 120.0 \\
\hline \multirow{2}{*}{$\begin{array}{l}\mathrm{CF}_{3}- \\
\text { N0 }\end{array}$} & C-F & 1.361 & 1.370 & 1.365 & 1.362 & 1.366 & 1.371 & 1.362 & 1.375 \\
\cline { 2 - 9 } & C-N & 1.802 & 1.581 & 1.600 & 1.550 & 1.565 & 1.547 & 1.595 & 1.542 \\
\cline { 2 - 9 } & N-0 & 1.245 & 1.225 & 1.228 & 1.223 & 1.228 & 1.225 & 1.222 & 1.225 \\
\cline { 2 - 9 } & F-C-F & 119.99 & 120.0 & 119.89 & 119.98 & 120.0 & 120.0 & 119.99 & 120.0 \\
\hline
\end{tabular}

The HOMO, LUMO and the energy gap ( $E_{\text {LUNO }}-E_{\text {HONO }}$ )of trifluorocarbon-nitro CF3-NO as a donor-acceptor system in table 3 are calculated by B3LYP density functional theory with many levels of theory. The energy gap for the new structure is take place in the range about (3.558-6.688) $\mathrm{eV}$ and the differences in the value of energy gap depend on the level used in calculation. Table 3 tells us that STO-3G give more larger value for band gap, this may be come from that level of theory is a small to describe the donor-acceptor systems in compared with large basis sets, such as, 6-31G(d) and 6-31G(d, p) levels of theory. Figure 2 shows the shapes of HOMO and LUMO drawn from the calculations of $6-31 \mathrm{G}(\mathrm{d}, \mathrm{p})$ basis sets, these shapes come from the distribution of electrons according to the linear combination atomic orbitals - molecular orbital, the high value of electro-negativity of fluorine atoms has the large contribution in HOMO and LUMO energies.

Table 3: HOMO, LUMO and energy gap for donoracceptor system

\begin{tabular}{|l|l|l|l|l|l|l|l|}
\hline Property & ST0-3G & $3-21 \mathrm{G}$ & $4-21 \mathrm{G}$ & $6-31 \mathrm{G}$ & $\begin{array}{l}6-31 \mathrm{G} \\
(\mathrm{d})\end{array}$ & $\begin{array}{l}6-31 \mathrm{G} \\
(\mathrm{d}, \mathrm{p})\end{array}$ & $6-311 \mathrm{G}$ \\
\hline H0M0 (eV) & -11.0208 & -10.2116 & -11.336 & -11.1255 & -11.0976 & -8.168470 & -10.5255 \\
\hline LUM0 (eV) & -4.3328 & -5.6401 & -4.9809 & -4.9986 & -5.3287 & -4.609543 & -5.02115 \\
\hline $\begin{array}{l}\text { Energy Gap } \\
(\mathrm{eV})\end{array}$ & 6.688 & 4.5715 & 6.3551 & 6.1269 & 5.7689 & 3.558927 & 5.50435 \\
\hline
\end{tabular}

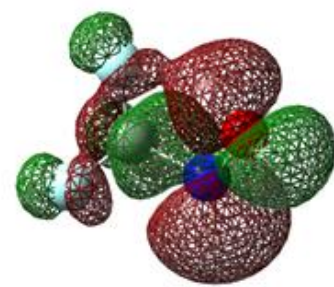

HOMO

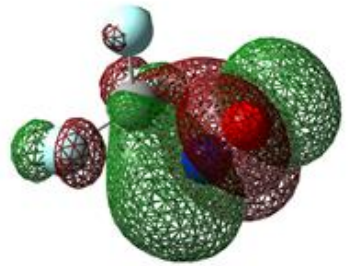

LUMO
Figure 2: $\mathrm{HOMO}$ and LUMO of $\mathrm{CF}_{3}-\mathrm{NO}$ structure

The results of ionization potential (IP), electron affinity (EA), chemical potential (K), electrophilicity index $(\mathrm{w})$ and charge transfer $(\Delta \mathrm{N})$ are presented in table 4. As we see from the above table, the largest value of charge transfer $(0.97745)$ between two systems (donor - acceptor) was results by employing B3LYP/6$31 \mathrm{G}(\mathrm{d}, \mathrm{p})$, this value corresponding to high ionization potential value $(11.0976 \mathrm{eV})$. This level of theory give good result for electrophilicity index $(\mathrm{w}=4.148 \mathrm{eV})$, this may help to interact this system with effective surrounding molecular system. The amount of charge transfer in $\mathrm{CF}_{3}$ - NO donor - acceptor system results from other basis sets gave approximately the same few lower value. The results of exact polarizability obtained from the calculations for donor, acceptor and donoracceptor system using B3LYP density functional theory with 6-31G (d, p). High polarizability means high chemical reactivity. The donor - acceptor system has more reactivity than other species in which the polarizability of this system is approximately twice the polarizability of the donor and four times the value of polarizability for acceptor, as we see in table 5. So the results satisfy that the tensors of polarizability in three dimensions are $\alpha_{\mathrm{xx}}<\alpha_{\mathrm{yy}}<\alpha_{\mathrm{zz}}$. 
Table 4: Electronic properties for donor-acceptor system

\begin{tabular}{|l|l|l|l|l|l|l|l|}
\hline Property & ST0-3G & $3-21 \mathrm{G}$ & $4.21 \mathrm{G}$ & $6.31 \mathrm{G}$ & $6-31 \mathrm{G}(\mathrm{d})$ & $6.31 \mathrm{G}(\mathrm{d}, \mathrm{p})$ & $6.311 \mathrm{G}$ \\
\hline $\mathrm{IP}(\mathrm{e})$ & 11.0208 & 10.2116 & 11.336 & 11.1255 & 11.0976 & 8.168470 & 10.5255 \\
\hline $\mathrm{EA}(\mathrm{eV})$ & 4.3328 & 5.6401 & 4.9809 & 4.9986 & 5.3287 & 4.609543 & 5.02115 \\
\hline $\mathrm{K}(\mathrm{eV})$ & 7.6768 & 7.92585 & 8.15845 & 8.06205 & 8.21315 & 6.3890065 & 7.773325 \\
\hline $\mathrm{W}(\mathrm{eV})$ & 2.6649 & 3.24592 & 1.60380 & 3.626424 & 3.935504 & 4.148544 & 4.00809 \\
\hline$\Delta \mathrm{N}$ & 0.80325 & 0.80042 & 0.678895 & 0.80056 & 0.97745 & 0.955676 & 0.89545 \\
\hline
\end{tabular}

Table 5: Average polarizability for donoracceptor system

\begin{tabular}{|l|l|l|l|l|}
\hline \multirow{2}{*}{ Species } & \multicolumn{4}{|l|}{ Polarizability (a. u) } \\
\cline { 2 - 5 } & $\alpha_{\mathrm{xx}}$ & $\alpha_{\mathrm{yy}}$ & $\alpha_{\mathrm{zz}}$ & $\alpha_{\mathrm{ave}}$ \\
\hline $\mathbf{C F}_{\mathbf{3}}$ & 5.142 & 13.268 & 13.269 & 10.559 \\
\hline NO & 3.987 & 3.987 & 9.457 & 5.81033 \\
\hline CF $_{\mathbf{3}}-$ & 15.988 & 18.098 & 26.415 & 20.167 \\
NO & & & & \\
\hline
\end{tabular}

The results of IR spectrum for $\mathrm{CF}_{3}-\mathrm{NO}$ donor-acceptor system are illustrated in table 5. The number of modes was calculated by the relation $3 \mathrm{~N}-5$, where $\mathrm{N}$ is the number of atoms in the structure, the bending of $\mathrm{C}-\mathrm{N}$ bond lies at $\left(745.55 \mathrm{~cm}^{-1}\right)$. For C-F bond, the stretching of B-F bond lies at $\left(1086.15 \mathrm{~cm}^{-1}\right)$ and the bending is at $\left(1436.83 \mathrm{~cm}^{-1}\right)$ in which it corresponds to intensity $(415.9089 \mathrm{Km} / \mathrm{mol})$. The large value of frequency $\left(1560.35 \mathrm{~cm}^{-1}\right)$ for the stretching of $\mathrm{N}-\mathrm{O}$ bond and it corresponds to $(75.015 \mathrm{Km} / \mathrm{mol})$ infrared intensity.

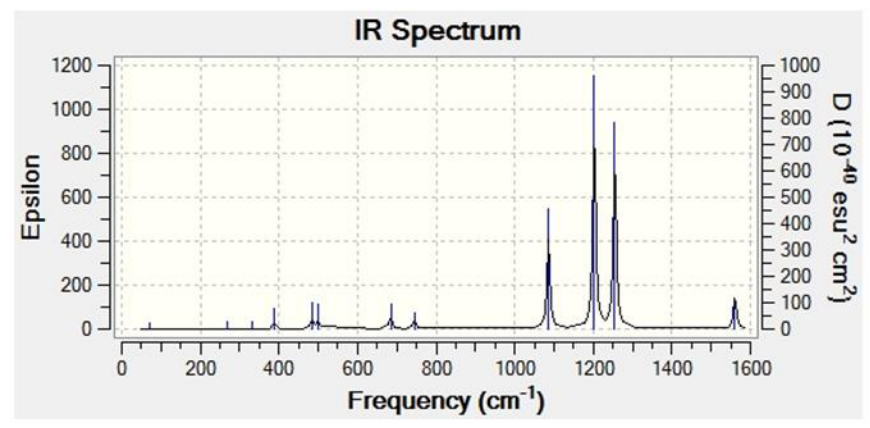

Figure 3: The IR spectrum of $\mathrm{CF}_{3}-\mathrm{NO}$ donor - acceptor system. Epsilon: intensity in $(\mathrm{Km} / \mathrm{mol})$

\section{Conclusions}

As we see from the results in this paper, the density functional theory used in this study is a powerful method and B3LYP functional is a suitable and an efficient function for studying the electronic properties of these structures. 6-31G $(\mathrm{d}, \mathrm{p})$ give a good agreement results for geometrical parameters with experimental data. The geometric structures, symmetry and total energies. The total energy for donor - acceptor molecular system declare that this structure is more stable and has high symmetry. The donor - acceptor system has large average polarizability comparing with donor and acceptor and this system has high reactivity than others. The results obtained in this work help us to select a type of bridges to interact the donor and acceptor to calculate the physical properties of donorbridge-acceptor, this idea came from the results of the energy gap for the structure, 6-31G $(\mathrm{d}, \mathrm{p})$ showed small energy gap in comparison with other used levels.

\section{References}

(1) Marcus, R. A.; Sutin, N. Biochim. Biophys. Acta 1985, 811, 265-322.

(2) Barbara, P. F.; Meyer, T. J.; Ratner, M. A. J. Phys. Chem. 1996, 100, 13148-13168.

(3) Bixon, M.; Jortner, J. AdV. Chem. Phys. 1999, 106, 35-208.

(4) Berlin, Y. A.; Kurnikov, I. V.; Beratan, D.; Ratner, M. A.; Burin, A. L. Top. Curr. Chem. 2004, 237, $1-36$.

(5) Matyushov, D. V.; Voth, G. A. ReV. Comp. Chemistry 2002, 18, 147-210.

(6) Adams, D. M.; Brus, L.; Chidsey, C. E. D.; Creager, S.; Creutz, C.; Kagan, C. R.; Kamat, P. V.; Lieberman, M.; Lindsay, S.; Marcus, R. A.; Metzger, R. M.; Michel-Beyerle, M. E.; Miller, J. R.; Newton, M. D.; Rolison, D. R.; Sankey, O.; Schanze, K. S.; Yardley, J.; Zhu, X. J. Phys. Chem. B 2003, 107, 6668-6697.

(7) Weiss, E. A.;Wasielewski, M. R.; Ratner, M. A. Top. Curr. Chem. 2005, 257, 103-133.

(8) Kuznetsov, A. M. Charge Transfer in Physics, Chemistry and Biology; Gordon \& Breach: New York, 1995.

(9) Kuznetsov, A. M.; Ulstrup, J. Electron Transfer in Chemistry and Biology; Wiley: Chichester,1999. 
(10) Balzani, V., Piotrowiak, P., Rodgers, M. A. J., Mattay, J., Astruc, D., Gray, H. B., Winkler, J., Fukuzumi, S., Mallouk, T. E., Haas, Y., de Silva, A. P., Gould, I., Eds.; Electron Transfer in Chemistry; Wiley-VCH Verlag GmbH: Weinheim, 2001; Vols. 1-5.

(11) Wasielewski, M. R. Chem. ReV. 1992, 92, 435461.

(12) Schuddeboom, W.; Ktijnen, B.; Verhoeven, J. W.; Staring, E. G. J.; Rikken, G. L. J. A.; Oevering, H. Chem. Phys. Lett. 1991, 179, 73-78.

(13) Ratner, M. A.; Jortner, J. In Molecular Electronics; Ratner,M. A., Jortner, J., Eds.; Blackwell:Oxford, UK, 1997; pp 5-72, and references therein.

(14) Lindsay, S. M.; Ratner, M. A. AdV. Mater. 2007, 19, 23-31.

(15) See, e.g., reviews published in Top. Curr. Chem.; Schuster, G. B., Ed.; Springer: Berlin, 2004; Vols. 236 and 237and references therein.

(16) Jordan, K. D.; Paddon-Row, M. N. Chem. ReV. 1992, 92, 395- 410 .

(17) Warman, J. M.; De Haas, M. P.; Verhoeven, J. W.; Paddon-Row, M. N. AdV. Chem. Phys. 1999, 106, 571-601.

(21) M. J. Frisch, G. W. Trucks, H. B. Schlegel et al., Gaussian 09, Revision A.02, Gaussian, Inc., PA, Wallingford CT. 2009.

(22) C. Lee, W. Yang, R.G. Parr, Phys. Rev. B 37 (1988) 785.

(23) A.D. Becke, Phys. Rev. A 38 (1988) 3098.(24)

A.D. Becke, J. Chem. Phys. 98 (1993) 5648. 